\section{Spirality of the Muscle Layers of the Intestine}

It is commonly stated in textbooks of Anatomy and Physiology that the layers of the muscularis externa are helically arranged; this attractive idea, with its functional implications, would seem to be attributable mainly to CAREY ${ }^{1}$. The bulk of experimental evidence, however, from the small and large intestines of several species, including man, lends little support to this concept of spirality of the muscle layers of the intestine (see Elsen and AREY ${ }^{2}$ ). Recently PACE and Wrlliams ${ }^{3}$ have found the circular layer of the muscularis externa of the human colon to be an 'expanding meshwork of interconnecting bands' and have suggested that it is a simple matter for the investigator to demonstrate the organisation in which he wishes to believe.

We have examined, by microdissection and by conventional histological methods, the circular layer of the muscularis externa of the rabbit distal colon. We find that the circular layer consists of quite distinct bundles (Figure 1) which, in the distended bowel, are stacked like the leaves of a Venetian blind (compare GoertTLeR ${ }^{4}$ ); these bundles lie at right angles to bundles of the longitudinal muscle layer. Each bundle in the circular muscle layer is composed of smooth muscle cells, virtually all of which lie along the long axis of the bundle; nevertheless, there are irregular interconnecting strands of muscular tissue which link contiguous bundles (Figure 2). When these interconnecting strands, which are thinner than the parent bundles, are broken during microdissection

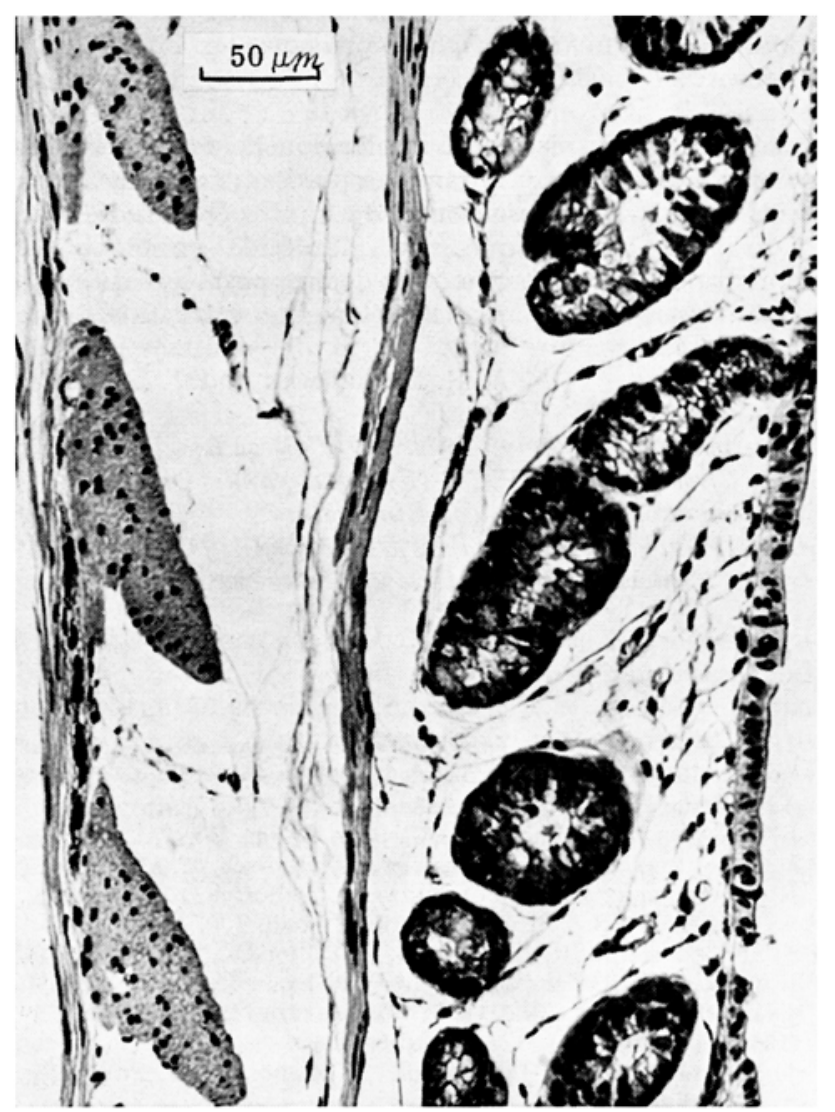

Fig. 1. A longitudinal section of rabbit distended distal colon. Note the separate bundles of the circular layer of the muscularis externa the thin strands of connective tissue between these bundles, and the regions of contact between the longitudinal and circular layers of the muscularis externa. The oral end of the section is uppermost. Stain H. and E. the bundles of the circular muscle layer occasionally come away in intact rings; moreover, a circular muscle bundle cannot be demonstrated to form more than one turn of a coil.

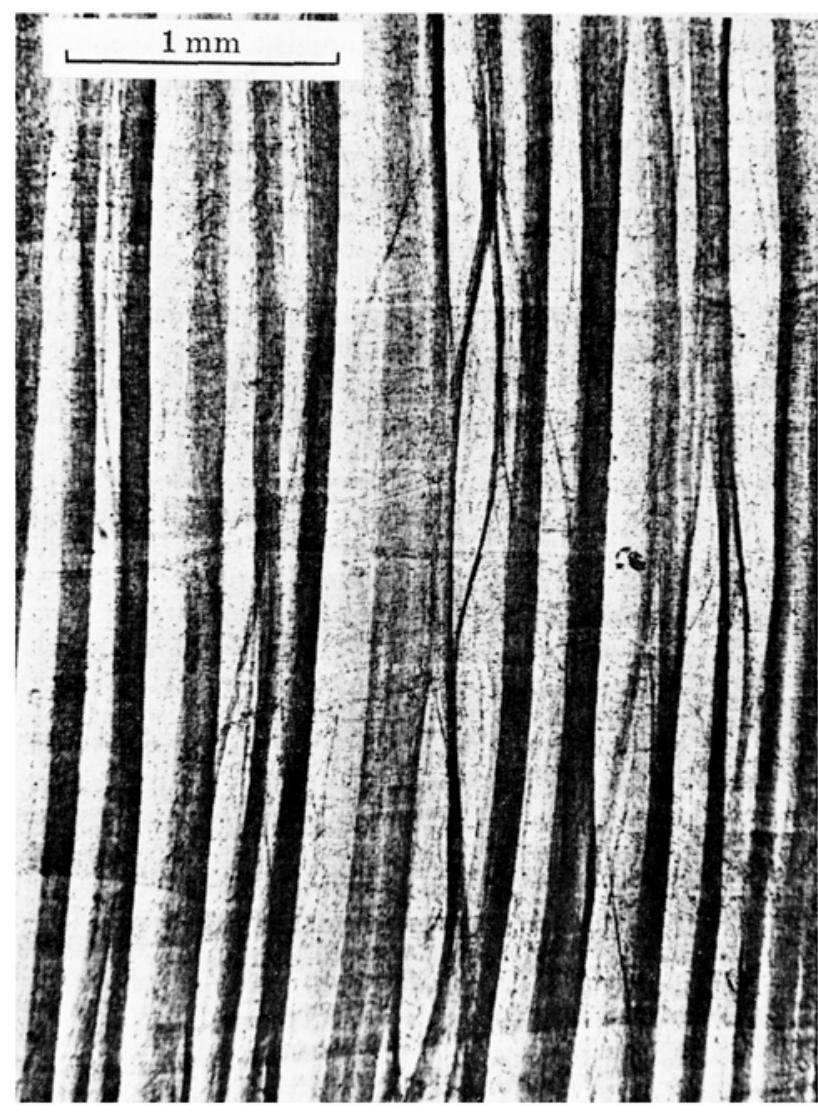

Fig. 2. A flat preparation of muscularis externa of rabbit distended distal colon. Note the bundles of circular muscle (in focus) and the interconnecting strands of muscular tissue. Stain H. and E.

The organisation of the circular layer of the muscularis externa of the rabbit distal colon would therefore seem somewhat simpler than that found by PACE and WILLrams in the human colon and although, by virtue of the interconnecting strands, the circular layer may behave as a spiral in a functional sense, the bundles of circular muscle certainly do not form part of an extensive helix in the structural sense envisaged by CAREY.

Résumé. On a étudié, par la microdissection et par les méthodes histologiques courantes, l'organisation de la couche circulaire de la muscularis externa du colon distal du Lapin. Les faisceaux de la couche circulaire ne font certainement pas partie d'une spirale extensive dans le sens structural, comme le décrit CAREY.

\section{H. C. McKirdy and Joyce Macmillan}

Institute of Physiology, University of Glasgow, Glasgow W.2 (Scotland), 31 December 1970.

1 E. J. Carey, Anat. Rec. 27, 189 (1921)

2 J. Elsen and L. B. Arey, Am. J. Anat. 118, 11 (1966).

3 J. L. PAce and I. Willlaims, Gut 70, 352 (1969).

- K. Goerttler, Morph. Jb. 69, 329 (1932). 